\title{
Experimental bariatric surgery in rats generates a cytotoxic chemical environment in the gut contents
}

\author{
Jia V. Li ${ }^{1,2+}$, Reshat Reshat ${ }^{1+}$, Qianxin Wu ${ }^{1}$, Hutan Ashrafian ${ }^{2,3}$, Marco Bueter $^{3}$, Carel W. le Roux ${ }^{3}$, Ara Darzi $^{2}$, \\ Thanos Athanasiou ${ }^{2}$, Julian R. Marchesi ${ }^{4}$, Jeremy K. Nicholson ${ }^{1,2}$, Elaine Holmes ${ }^{1 *}$ and \\ Nigel J. Gooderham ${ }^{1 *}$ \\ Section of Biomolecular Medicine, Department of Surgery and Cancer, Imperial College London, London, UK \\ 2 Section of Biosurgery and Surgical Technology, Department of Surgery and Cancer, Imperial College London, London, UK \\ ${ }^{3}$ Section of Investigative Medicine, Division of Diabetes, Endocrinology and Metabolism, Department of Medicine, Faculty of Medicine, Imperial College London, \\ London, UK \\ ${ }^{4}$ School of Biosciences, Cardiff University, Cardiff, UK
}

\section{Edited by:}

Peter J. Turnbaugh, Harvard

University, USA

\section{Reviewed by:}

Peter J. Turnbaugh, Harvard

University, USA

Alain Stintzi, Ottawa Institute of

Systems Biology, Canada

*Correspondence:

Elaine Holmes, Biomolecular Medicine, Department of Surgery and

Cancer, Imperial College London,

London SW7 2AZ, UK.

e-mail: elaine.holmes@imperial.ac.uk;

Nigel J. Gooderham, Biomolecular

Medicine, Imperial College London,

Sir Alexander Fleming Building,

London SW7 2AZ, UK.

e-mail:n.gooderham@imperial.ac.uk

+ Jia V. Li and Reshat Reshat have contributed equally to this work.
Bariatric surgery, also known as metabolic surgery, is an effective treatment for morbid obesity, which also offers pronounced metabolic effects including the resolution of type 2 diabetes and a decrease in cardiovascular disease and long-term cancer risk. However, the mechanisms of surgical weight loss and the long-term consequences of bariatric surgery remain unclear. Bariatric surgery has been demonstrated to alter the composition of both the microbiome and the metabolic phenotype. We observed a marked shift toward Gammaproteobacteria, particularly Enterobacter hormaechei, following Roux-en-Y gastric bypass (RYGB) surgery in a rat model compared with sham-operated controls. Fecal water from RYGB surgery rats was highly cytotoxic to rodent cells (mouse lymphoma cell line). In contrast, fecal water from sham-operated animals showed no/very low cytotoxicity. This shift in the gross structure of the microbiome correlated with greatly increased cytotoxicity. Urinary phenylacetylglycine and indoxyl sulfate and fecal gamma-aminobutyric acid, putrescine, tyramine, and uracil were found to be inversely correlated with cell survival rate. This profound co-dependent response of mammalian and microbial metabolism to RYGB surgery and the impact on the cytotoxicity of the gut luminal environment suggests that RYGB exerts local and global metabolic effects which may have an influence on long-term cancer risk and cytotoxic load.

Keywords: obesity, bariatric surgery, Roux-en-Y gastric bypass, microbial profile, 16S rRNA, metabolic profile, cytotoxicity, gammaproteobacteria

\section{INTRODUCTION}

Obesity is worldwide epidemic with 1.5 billion adults (age $>20$ years) and 43 million children under the age of 5 overweight, of which approximately 500 million are clinically obese (BMI > 30; WHO, 2006). Obesity and its comorbidities impose a substantial healthcare burden which are associated with mounting international healthcare costs (Eckel et al., 2005; Ashrafian et al., 2011c). Although several treatment strategies such as lifestyle modification (Wing and Phelan, 2005) and medications have been used to combat obesity, their long-term efficacy has yet to be demonstrated. Bariatric surgery, also called weight loss or metabolic surgery, was introduced 50 years ago to provide drastic weight loss in morbidly obese patients (Kremen et al., 1954; Ashrafian et al., 2010) and is now increasingly used to treat patients with lower adiposity, or occasionally purely for metabolic benefit (Ashrafian et al., 2011b). Currently the three most common types of bariatric surgery are the Roux-en-Y gastric bypass (RYGB), Adjustable Gastric Band and the Sleeve Gastrectomy. Of these, the RYGB is considered to be the "gold standard" procedure due to its established efficacy, metabolic benefits, and safety from side effects. Typically the RYGB operation is performed laparoscopically and consists of the creation of a small stomach pouch $(30-50 \mathrm{ml})$ that is divided from a larger gastric remnant. The small bowel (jejunum) is bypassed approximately $50 \mathrm{~cm}$ below the stomach outlet ("biliopancreatic limb") in a Y-structured configuration. This anatomical rearrangement allows food from the outlet of the small stomach pouch to enter directly into the small intestine ("alimentary limb"). Both biliopancreatic and alimentary limbs are attached to a "common channel" to complete the Y-configuration (Ashrafian et al., 2010). This surgical procedure induces a series of physical and metabolic sequelae characterized as the BRAVE effects: Bile flow alteration; Reduction of gastric size; Anatomical gut rearrangement and altered flow of nutrients; Vagal manipulation; and Enteric gut hormone modulation (Ashrafian et al., 2010) leading to effective weight loss and resolution of type 2 diabetes.

Modulation of the enteric gut microbiota has been reported in both animal and human clinical studies post-RYGB surgery, although whether these changes are etiopathogenic or consequential is not yet clear. A direct effect on the microbiota postRYGB surgery (Zhang et al., 2009) where a dramatic increase in the gammaproteobacteria population compared with control and obese subjects was demonstrated in a clinical study. This 
finding was supported by similar observation in an experimental RYGB study in rats. Other studies have characterized the indirect effects of RYGB in altered gut microbial metabolites or microbial-mammalian co-metabolites in biofluids. Serum sphingosines, unsaturated fatty acids, and branched chain amino acids altered significantly in obese patients within 3 months post-RYGB (Mutch et al., 2009). This study also found a strong negative correlation between serum nervonic acid concentrations and insulin resistance (HOMA-IR). In a separate weight loss control study, amino acids and branched chain amino acids were found to decrease post-RYGB but not after dietary intervention, which suggested the down-regulation of amino acids may contribute to the glucose homeostasis and thus improve the metabolic status (Laferrere et al., 2011). Using a rat RYGB model, we previously characterized the correlation between the metabolic and metagenomic profiles following RYGB surgery (Li et al., 2011). Metabolic effects of surgery included a reduction in levels of TCA cycle intermediates, increased amine production (methylamine, trimethylamine, and putrescine), and increased production of microbialderived metabolites such as propionate and 5-aminovalerate, or microbial-host co-metabolites (e.g., hippurate, 4-cresyl sulfate, 4-cresyl glucuronide, 4-hydroxyphenylacetate, and phenylacetylglycine). These microbial-related metabolites were positively associated with Gammaproteobacteria, particularly, with Enterobacter hormaechei and negatively associated with Clostridia (Li et al., 2011).

Epidemiological analyses suggest that reduced risks of cardiovascular disease and cancer (especially colonic) are long-term benefits of bariatric surgery, but the molecular mechanisms of these associations are poorly understood (Ashrafian et al., 2011a). As there is a general reduction in the incidence of cancer following RYGB surgery in man (Adams et al., 2007; Sjostrom et al., 2009) and there is a marked and long-term stable alteration in fecal bacterial composition following surgery we hypothesized that the protective effects of bariatric surgery could be mediated by the altered bioavailability of microbial cytotoxins and genotoxins. Fecal matter has been shown to be genotoxic (Lee et al., 2005), and it is well-established that diet-related fecal cytotoxicity and genotoxicity are strongly correlated with colon cancer risk (de Kok and van Maanen, 2000). Thus, it is possible that bariatric surgery modifies diet-associated exposure to cancer-inducing chemicals and this might be expected to influence the diet-borne genotoxic burden in the exposome. Hence, in order to determine the influence of bariatric surgery on the cytotoxic and genotoxic burden of fecal material, fecal water extracts obtained from RYGB and sham-operated rats were analyzed using a well-established in vitro mammalian cell mutation assay. Contrary to our initial hypothesis we found dramatically increased cytotoxicity in the fecal water of rats post-RYGB surgery, which prompts further questions as to the suitability of the rat as a model for RYGB surgery.

\section{MATERIALS AND METHODS ANIMAL MODEL}

The animal experiment was carried out under a license authorized by the UK Home office (PL 70-6669) and the experiment details have been previously described in Li et al. (2011). Briefly, 12 male Wistar rats (non-obese) were housed in individual cages and kept under a 12/12-h light/dark cycle at a room temperature of $21 \pm 2^{\circ} \mathrm{C}$. All rats were administered intraperitoneally with $1 \mathrm{ml}$ amoxicillin/flucloxacillin solution (both at $12.5 \mathrm{mg} / \mathrm{ml}$ ) pre-operation as standard prophylaxis against post-operative sepsis, both sham and RYGB rats received antibiotics to control antibiotic-related variations including the modulation of gut microbiota. This is consistent with common practice in human clinical operations. A total of six rats were subject to RYGB surgery RYGB whilst the others underwent a sham procedure and served as the control group. Fecal and urine samples were collected for $24 \mathrm{~h}$ pre-operation and at 2, 4, 6 and 8 weeks post operation.

\section{CELL CULTURE}

Mouse lymphoblastoid L5178Y cells were obtained from ATCC. L5178Y cells were cultured in RPMI 1640 media supplemented with $10 \%_{\mathrm{v} / \mathrm{v}}$ heat inactivated horse serum, $2 \mathrm{mM} \mathrm{L}$-glutamine, $0.1 \%_{\mathrm{v} / \mathrm{v}}$ F68 pluronic, $100 \mathrm{units} / \mathrm{ml}$ penicillin, and $100 \mu \mathrm{g} / \mathrm{ml}$ streptomycin (Clements, 2000).

\section{FECAL WATER EXTRACTION}

In order to ensure the reproducibility of the fecal extraction and cell treatment, two separate experiments were performed. Firstly, a fecal pellet from each of six sham and six RYGB-operated rats at weeks 2 and 8 post operation were weighed $(\sim 200 \mathrm{mg})$ and homogenized in distilled water by vigorously vortexing. A separate pellet for each animal was pipetted into a 2-ml Eppendorf ${ }^{\mathrm{TM}}$, containing $1.4 \mathrm{ml}$ of $0.2 \mathrm{M}$ sodium phosphate buffer $(\mathrm{pH}=7.4)$ containing $20 \%$ deuterium oxide $\left(\mathrm{D}_{2} \mathrm{O}\right)$ as a magnetic field lock, $0.01 \% 3$-(trimethylsilyl)-[2,2,3,3- $\left.{ }^{2} \mathrm{H}_{4}\right]$ propionic acid sodium salt (TSP) as a spectral reference, and $3 \mathrm{mM}$ sodium azide to terminate any bacterial activity, and homogenized. The sample was then vortexed for $15 \mathrm{~s}$, sonicated for $30 \mathrm{~min}$ at $25^{\circ} \mathrm{C}$ and centrifuged at $10392 \mathrm{~g}$ for $20 \mathrm{~min}$. A total of $700 \mu \mathrm{l}$ supernatant was taken into a 1.5-ml Eppendorf ${ }^{\mathrm{rM}}$ tube and centrifuged again under the same conditions after which the supernatant $(600 \mu \mathrm{l})$ was taken into an NMR tube. A third pellet was used to generate the $16 \mathrm{~S}$ rRNA data.

In the second experiment, four of the RYGB and four shamoperated rats were randomly selected for further investigation. Here, fecal pellets collected for each rat at each time point (presurgery and 2, 4, 6, and 8 weeks post surgery) were homogenized and extracted to follow a more refined time course. Samples were then split into two aliquots for cytotoxicity/genotoxicity assays and NMR analysis. All fecal extracts were then sterile filtered through a $0.2-\mu \mathrm{m}$ membrane and the same volume of fecal extract equivalent to $20 \mathrm{mg}$ were used in cytotoxicity and genotoxicity assays. Fecal pellet extracts for NMR analysis were mixed with $1.4 \mathrm{ml}$ of the aforementioned phosphate buffer. The mixture was centrifuged at $1.0 \times 10^{4} \mathrm{~g}$ for $20 \mathrm{~min}$ and $600 \mu \mathrm{l}$ of supernatant transferred into a 5-mm outer-diameter NMR tube (Beckonert et al., 2010).

\section{CYTOTOXICITY AND GENOTOXICITY ASSAY}

Cytotoxicity and genotoxicity evaluation was performed as described by Clements according to OECD guidelines (OECD, 1997; Clements, 2000). In brief, four million exponentially growing L5178Y cells were treated with sham or RYGB-operated fecal 
water extract for $24 \mathrm{~h}$ at $37^{\circ} \mathrm{C}, 5 \% \mathrm{CO}_{2}$. The final treatment concentration was $1 \mathrm{mg}$ fecal material per $1 \mathrm{ml}$ cell suspension media. As a negative control, fecal water extract was replaced with water. Ethyl methanesulfonate (EMS, $20 \mu \mathrm{g} / \mathrm{ml}$ ) and/or etoposide $(73.5 \mathrm{ng} / \mathrm{ml})$ were used as positive controls, unless otherwise stated. Following treatment, L5178Y cells were washed, counted, and the concentration of cells adjusted to $1.5 \times 10^{5} / \mathrm{ml}$ to maintain exponential growth. Treated L5178Y cells were counted and subcultured daily for a further 2 days to determine the relative suspension growth (RSG; a measure of cell death and proliferative ability following treatment relative to the negative control (Clements, 2000). On the third day, L5178Y cells were plated at 1.6 cells per well in 96 well plates to determine the cloning efficiency and 2,000 cells per well in trifluorothymidine $(4 \mu \mathrm{g} / \mathrm{ml})$ to determine the Thymidine kinase $(t k)$ mutant frequency. Plates were incubated for 14 days at $37^{\circ} \mathrm{C}, 5 \% \mathrm{CO}_{2}$ and then colonies were scored.

\section{NMR-BASED METABOLIC PROFILING OF FECAL WATER AND URINE}

For each fecal pellet extract and urine sample 1-Dimensional proton NMR spectra of urine and fecal extracts were acquired using a Bruker $600 \mathrm{MHz}$ spectrometer (Bruker, Rheinstetten, Germany) with a standard NMR pulse sequence (recycle delay-90- $t_{1}(3 \mu \mathrm{s})$ $90-t_{\mathrm{m}}(100 \mathrm{~ms})-90$-acquisition) at $27^{\circ} \mathrm{C}$. Water suppression was achieved using selective irradiation during a recycle delay of $2 \mathrm{~s}$ and $t_{\mathrm{m}}$, and a $90^{\circ}$ pulse was $10 \mu \mathrm{s}$ (Beckonert et al., 2010). A total number of 128 scans were accumulated into $64 \mathrm{k}$ data points for each urine spectrum with a width of $20 \mathrm{ppm}$, whereas for fecal water extracts, 512 scans were acquired due to the low concentration of the samples.

\section{MICOBIAL PROFILING VIA PYROSEQUENCING}

The composition on the gut microbiota was determined by undertaking a survey of the 16S rRNA genes in each animal. A modified protocol based on the Qiagen Stool Kit (Qiagen, Crawley, UK) with an additional bead beating step to homogenize and lyse bacteria in the samples $(0.1 \mathrm{~g} 0.1 \mathrm{~mm}$ sterile glass beads, $3 \times 4500 \mathrm{rpm}$ for $30 \mathrm{~s}$ with $5 \mathrm{~min}$ on ice in between cycles) was used to extract DNA from $250 \mathrm{mg}$ fecal pellets (Cole et al., 2009; Schloss et al., 2009). The extracted DNA was quantified using the Invitrogen Qubit platform and diluted to a working concentration of $10 \mathrm{ng}$ $\mu \mathrm{l}^{-1}$. PCR was used to amplify the V1-V3 regions of the $16 \mathrm{~S}$ rRNA gene from each DNA sample using the primers as published in (Li et al., 2011). PCR mixtures $(25 \mu \mathrm{l})$ contained $1 \times$ Buffer (20 mM Tris pH 8.4, $50 \mathrm{mM} \mathrm{KCl}$ ), $1.5 \mathrm{mM} \mathrm{MgCl}_{2}, 200 \mu \mathrm{M}$ of each dNTP, 1.25 U of Taq polymerase (NEB, UK), 5 pmol of each primer, and $10 \mathrm{ng}$ of DNA. PCR was performed in triplicate on all DNA extracts using a MJ Research PTC-200P Thermal Cycler (MJ Research, USA). The PCR conditions were: $95^{\circ} \mathrm{C}$ for $5 \mathrm{~min}$ initial denaturation, followed by 25 cycles of amplification at $95^{\circ} \mathrm{C}$ denaturation for $30 \mathrm{~s}$, annealing at $55^{\circ} \mathrm{C}$ for $40 \mathrm{~s}$, and extension of $72^{\circ} \mathrm{C}$ for $1 \mathrm{~min}$, with a final extension of $72^{\circ} \mathrm{C}$ for $5 \mathrm{~min}$. Pooled PCR products for each sample were purified using a Qiagen PCR purification kit, quantified and equimolar amounts pooled prior to running on a $1 / 4$ of a PTP (Pico titer plate) using titanium chemistry (AGOWA, Berlin, Germany). The sequences were binned by sample source and any reads that were less than 250 bp were removed. The filtered sequences were classified using the RDP classifier and the relative proportions of phyla and families determined. Community analysis of the data was undertaken using MOTHUR.

\section{STATISTICAL CORRELATION ANALYSIS}

${ }^{1} \mathrm{H}$ NMR spectra were phased, calibrated to TSP $\delta 0.0$, and baselinecorrected using an in house developed MATLAB script. The pre-processed NMR spectra were then imported into MATLAB (R2010b) platform with a resolution of $0.0005 \mathrm{ppm}$ and water peak $(\delta 4.7-4.9)$ and noise containing regions $(\delta 0-0.3,9.4-10.0)$ were removed to reduce the number of data points. The remaining spectral data were normalized using probabilistic quotient normalization method and then performed multivariate statistical data analysis (Trygg et al., 2007) including principal component analysis (PCA) and projection on latent structures (PLS) regression analysis. Statistical analysis used to calculate significance in cytotoxicity and genotoxicity assays was one way ANOVA with Dunnett's post hoc test compared to the negative control Correlation of the cytotoxicity values with the $16 \mathrm{~S}$ rRNA profiles was also carried out.

\section{RESULTS}

\section{CYTOTOXICITY AND GENOTOXICITY OF FECAL EXTRACTS}

Fecal samples from a total of 12 rats at weeks 2 and 8 post operation were used for cytotoxicity, genotoxicity, and microbial composition evaluation. Cytotoxicity is reported as the RSG of the cells following treatment; a measure of cell cycle arrest, cell death, and clonogenicity. Unexpectedly, all RYGB samples exhibited strong cytotoxic responses compared with sham samples $(p<0.001$, Figure 1A). No significant difference in toxicity was observed between the 2 and 8 -week time points within the same group. However, the mean RSG of RYGB-operated rats was markedly lower than the sham-operated controls ( $p<0.001$; Figure 1A). Fecal water samples were also examined for genotoxicity using the TK locus in the regulatory acceptable Mouse Lymphoma L5178Y mutation assay. Genotoxicity above the spontaneous background rate $\left(85 \times 10^{-6}\right)$ was not observed with fecal water extracts from RYGB or sham-operated rats (Figure 1B), whereas the positive genotoxic control, EMS $(20 \mu \mathrm{g} / \mathrm{ml})$ gave a mutation frequency of 240 mutant clones per $10^{6}$ cells.

In order to ensure the reproducibility of the experiments, 8 of the 12 rats were randomly selected (four sham and four RYGB) and the analysis repeated using additional sampling time points (preop, 2, 4, 6, and 8 weeks post-op). The RSG values of L5178Y mouse lymphoma cells exposed to RYGB fecal water extracts for $24 \mathrm{~h}$ was markedly lower than sham extracts (Figure 2), indicating that RYGB fecal water was toxic to the cells compared with sham fecal water, which is consistent with the results derived from the initial observation using six rats at two post-operative time points. However, cell survival following sham operation was more variable than RYGB surgery (Figure 2). Neither the sham nor the RYGB group pre-surgery fecal water extracts were cytotoxic. Thus, the cytotoxicity observed in our experiments directly resulted from RYGB surgery. As expected, the positive cytotoxic control (etoposide) induced cytotoxicity. 


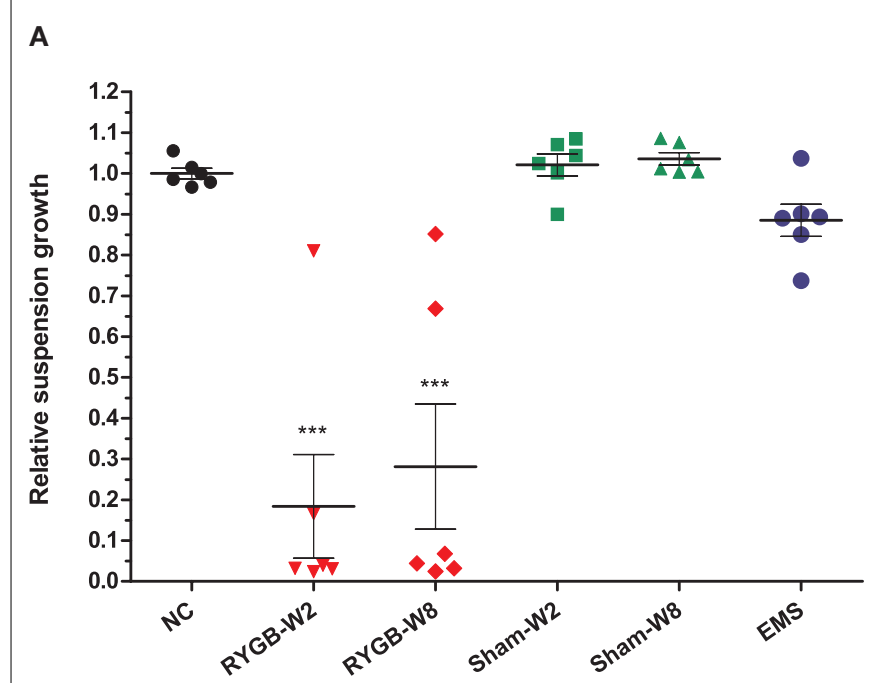

FIGURE 1 | Determination of the relative suspension growth as a measure of cytotoxicity (A) and genotoxicity (B) of fecal water extracts following treatment of L5178Y mouse lymphoblastoid cells for $\mathbf{2 4} \mathbf{h}$. Data
B

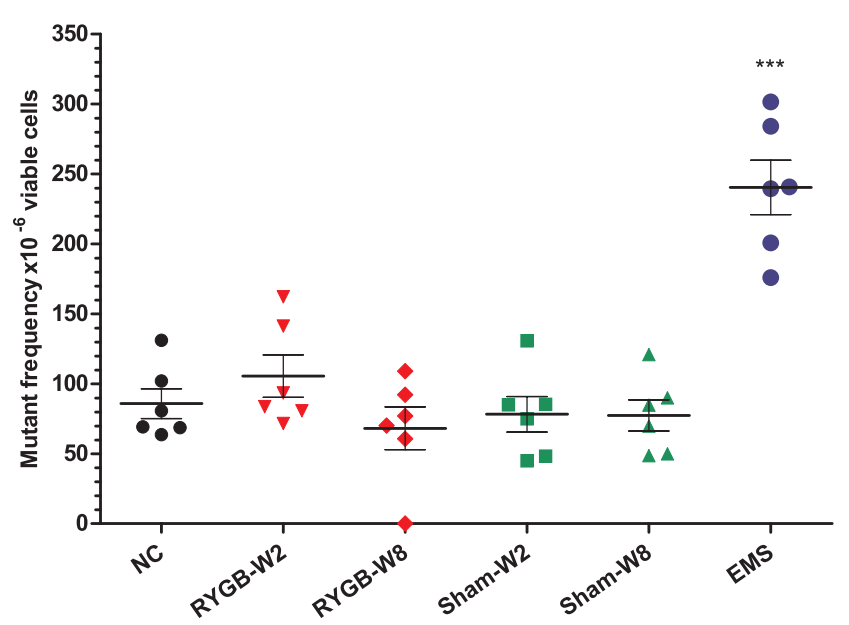

represent mean \pm SEM of six independent samples. The negative control (NC) replaced fecal material with water and EMS $(20 \mu \mathrm{g} / \mathrm{ml})$ was used as a positive genotoxin. ${ }^{* *} p<0.001$ vs. negative control by one way ANOVA test.

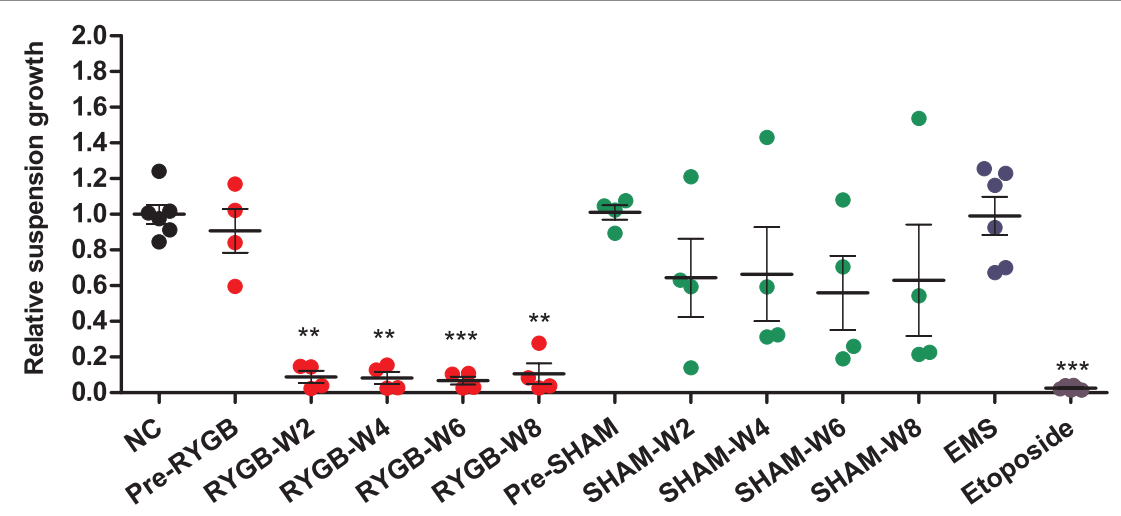

FIGURE 2 | Determination of the relative suspension growth (RSG) of L5178Y mouse lymphoblastoid cells after $24 \mathrm{~h}$ exposure to individual fecal water extracts from four sham and four RYGB-operated rats at pre-surgery, 2, 4, 6, and 8 weeks post surgery. The negative control (NC) replaced fecal material with water and EMS $(20 \mu \mathrm{g} / \mathrm{ml})$ was used as a positive genotoxin whilst etoposide $(73.5 \mathrm{ng} / \mathrm{ml})$ was used as a positive cytotoxin. ${ }^{* *} p<0.01,{ }^{* *} p<0.001$ vs. negative control by one way ANOVA test.

\section{MICROBIAL-METABOLIC-CYTOTOXICITY AXIS}

To understand the relationship between the microbiota, metabolites, and the extent of cytotoxicity observed in our cell culture system, a statistical integration method was applied to correlate multiple datasets. O-PLS regression analysis was performed to identify correlation between (i) the NMR fecal and urine extracts and RSG values (Figures 3A,B) and (ii) the RSG values and selected bacterial families (Figure 4). The fecal aromatic amino acid tyrosine was found to be positively correlated with cell survival whereas fecal tyramine, uracil, glycine, gamma-aminobutyric acid (GABA) and putrescine, and urinary indoxyl sulfate, phenylacetylglycine, 4cresyl glucuronide, 4-cresyl sulfate, 4-hydroxylphenylacetate, formate, and 5-aminovalerate appeared to be associated with lower RSG levels.

To enhance the correlation strength and minimize the interanimal variation, the fecal water extracts from four rats sampled at five time points as described above were subjected to NMR spectroscopic analysis in the second experiment. A direct O-PLS correlation analysis was applied based on fecal water NMR profiles and RSG from cytotoxicity profiles (Figure 3C). The metaboliccell growth correlation was consistent with aforementioned results from the initial dataset but with a stronger $\left(Q^{2} Y=0.55\right)$ and clearer model, where tyramine, methylamine, pyruvate, GABA, and putrescine were directly associated with cell death whereas butyrate, known as a major nutrient of colonic cells, was positively correlated with cell survival.

To investigate the association between the observed changes in the microbiome at a gross level and cytotoxicity levels, 22 bacterial familial levels were correlated with RSG of the cells following fecal water treatment. Enterobacteriaceae, Pasteurellaceae, Lachnospiraceae, and Ruminococcaceae levels were found to be significantly $(p<0.01)$ correlated with RSG of the cells following 

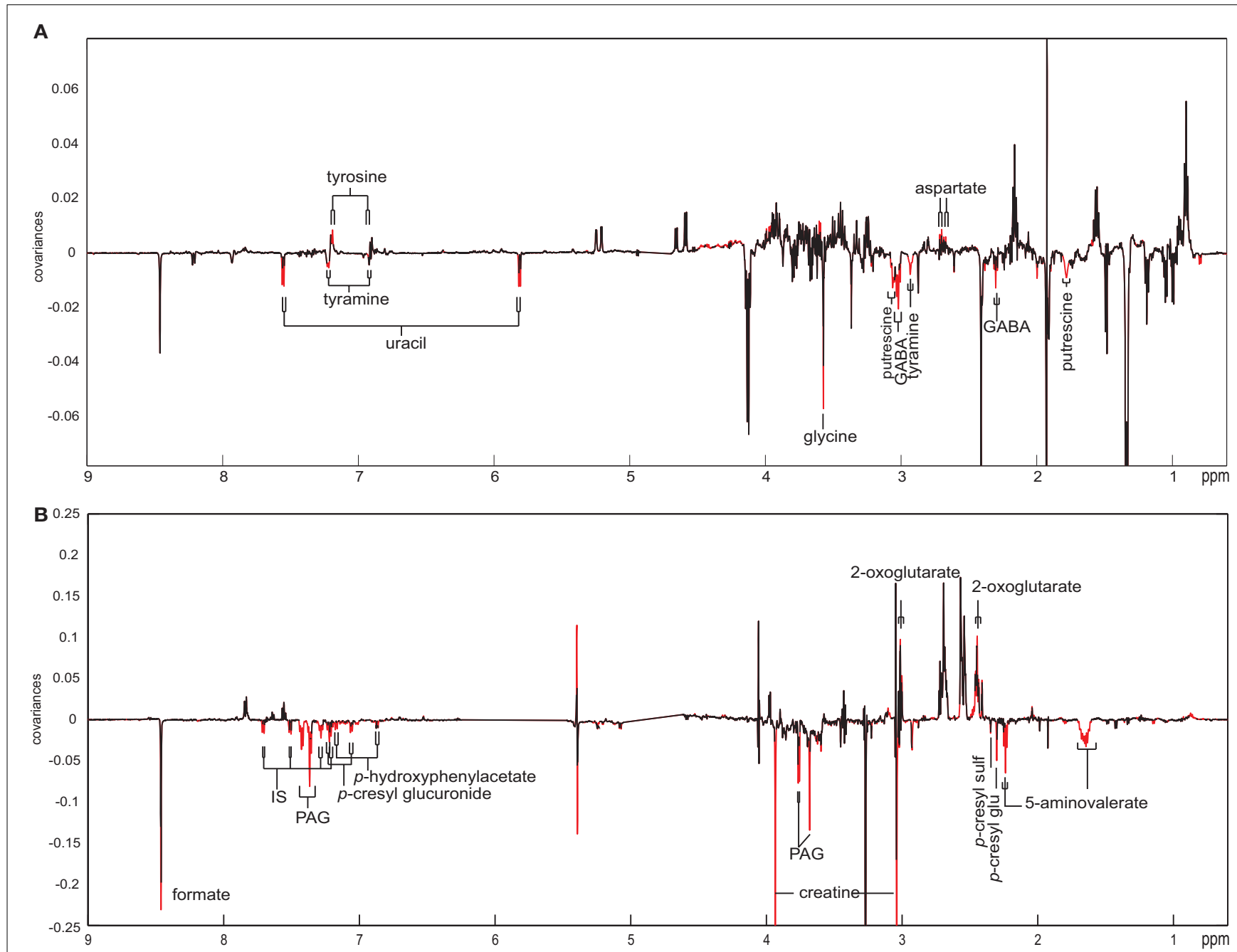

C

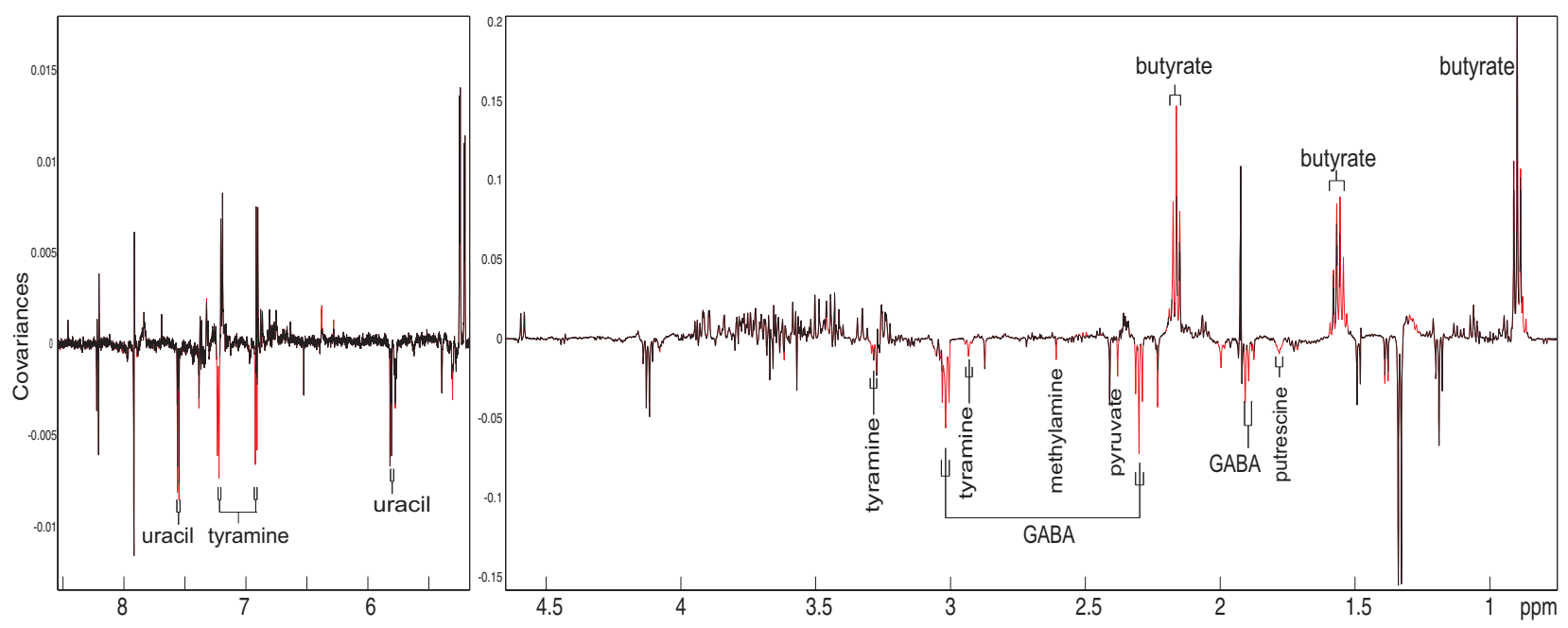

FIGURE 3 | O-PLS regression analyses of fecal water (A) and urine extracts (B) against relative suspension growth values obtained from a 24-h treatment of L5178Y cells with sham or RYGB-operated rat fecal extracts (week 2 and week 8) or O-PLS regression analyses of fecal water extracts against relative suspension growth obtained from $24 \mathrm{~h}$ treatment of L5178Y cells with two sham or two RYGB fecal water extracts [pre-surgery and $\mathbf{2 , 4 , 6}$, and 8 weeks post surgery (C)]. Peaks pointing upward in the loadings plots represent the metabolites are positively correlated to the cell growth and visa versa. Red peaks reach a significance level of $p<0.005$. Keys: GABA, gamma-aminobutyric acid; IS, indoxyl sulfate; PAG, phenylacetylglycine; $p$-cresyl sulf, $p$-cresyl sulfate; $p$-cresyl glu, $p$-cresyl glucuronide. 

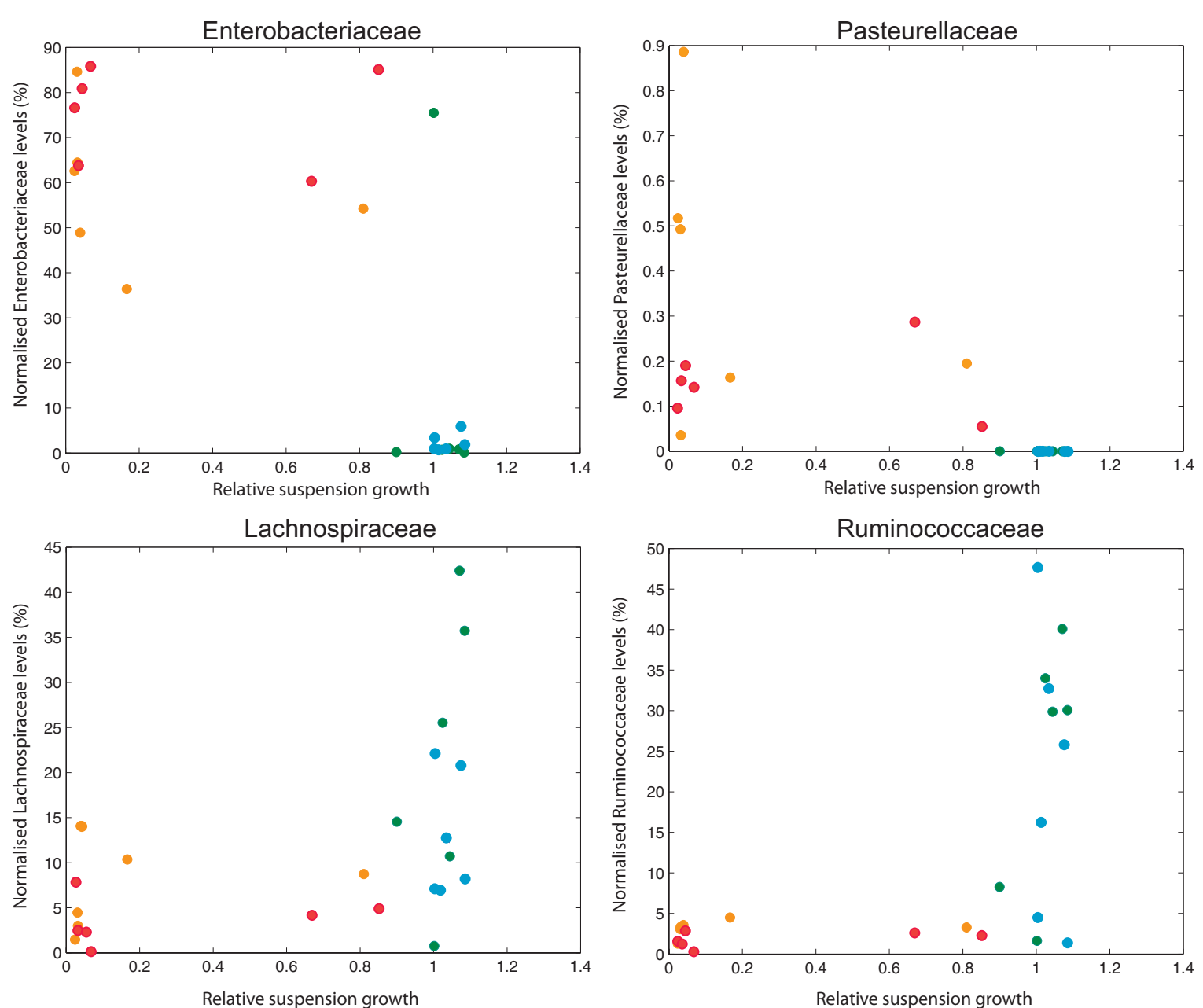

FIGURE 4 | Scatter plots of normalized bacterial levels (Enterobacteriaceae, Pasteurellaceae, Lachnospiraceae, and Ruminococcaceae) and relative suspension growth of L5178Y mouse lymphoblastoid cells exposed to fecal water extracts of six sham and six RYGB rats at weeks 2 and 8 post intervention. Orange: RYGB-2 weeks post op; Red: RYGB-8 weeks post op; Green: Sham-2 weeks post op; Blue: Sham-8 weeks post op.

treatment and the scatter plots of normalized bacterial levels and RSG values are illustrated in Figure 4. Levels of Enterobacteriaceae and Pasteurellaceae appear to be inversely correlated with cell survival, whereas levels of Lachnospiraceae and Ruminococcaceae were positively related to the RSG.

\section{DISCUSSION}

Contrary to our initial expectations, based on recent epidemiological findings that bariatric surgery is associated with lower cancer risk, this exploratory study has clearly shown that RYGB surgery in a Wistar rat model increases the cytotoxicity of fecal matter as indicated by marked reduction in (RSG) as a measure of cell death in a well-established rodent reporter cell line. Furthermore, this cytotoxicity profile of fecal water post-RYGB operation was strongly correlated with the fecal and urinary metabolic phenotypes with fecal concentrations of putrescine, uracil, tyramine, GABA, and methylamine being inversely correlated with cell survival, whereas butyrate was positively associated with cell survival. In addition to the correlation between fecal amines and cell death, several urinary metabolites also demonstrated an inverse correlation with cell survival, including indoxyl sulfate, phenylacetylglycine, 4-cresyl glucuronide, 4-cresyl sulfate, 4-hydroxylphenylacetate, formate, and 5-aminovalerate.

\section{UPREGULATION OF AMINE METABOLISM}

Putrescine is a polyamine found ubiquitously in eukaryotic cells and is vital for cell growth (Tabor and Tabor, 1984; Pegg, 1988). However, high intracellular polyamine accumulation, either from an imbalance in the cellular homeostatic mechanisms or exogenous supply, could have a deleterious effect on cell survival (Marton et al., 1991; Davis et al., 1992; Casero and Pegg, 1993; Buckton and Machiste, 1997). For example, treating polymorphonuclear cells with $1 \mathrm{mM}$ putrescine for $30 \mathrm{~min}$ resulted in the induction of apoptosis, possibly through a caspase specific pathway (Mariggio et al., 2004). Further to this, administration of an exogenous supply of putrescine has been shown to result in intracellular accumulation with ensuing apoptosis in a hepatoma cell line (Tome et al., 1997) and in a mouse myeloma cell line (Tobias and Kahana, 1995). 
Our study revealed a post-operative increase in fecal putrescine levels that correlated with the degree of fecal cytotoxicity based on a cell based assay, and may contribute to the induction of cell death following RYGB.

One likely mechanism for the rise in fecal putrescine after surgery may reflect the microbial catabolism of incompletely digested proteins reaching the colon as a result of surgical bypass of the foregut (Welters et al., 1999; Li et al., 2011). Alternatively the increase in post-operative fecal putrescine levels may occur as a result of its anti-inflammatory properties. Intracellular polyamines such as putrescine are known to possess powerful anti-inflammatory properties (Lovaas and Carlin, 1991) and have been demonstrated as a response to gut and liver inflammation (Bird et al., 1983). Using a carrageenan-induced edema rat model, putrescine was found to possess a tenfold higher antiinflammatory activity than spermidine (Bird et al., 1983). The increase in polyamines is likely to negatively modulate the immune response through its action on leukocyte activity (Ferrante et al., 1986; Quemener et al., 1994). We and others (Evrard et al., 1993) have noted that bariatric surgery induces significant macroscopic trophic changes in the intestinal mucosa of animal models (more than two-fold increase in mucosal mass) that may reflect an increased post-operative gut inflammatory state. Consequently a post-operative increase in fecal putrescine may occur as an anti-inflammatory response to surgically induced inflammation.

Gamma-amino butyric acid, an inhibitory neurotransmitter in the mammalian central nervous system, is also increased in fecal samples post-RYGB and was found to inversely correlate with cell survival in our cytotoxicity assays. The increased GABA concentration in fecal water could be due to the high putrescine level as GABA can be derived from the microbial processing of putrescine (Kurihara et al., 2010). Increased expression of fecal GABA is consistent with the well-defined increase in glucagon-like peptide (GLP-1) after RYGB surgery (Ashrafian and le Roux, 2009). GABA stimulates GLP-1 release from intestinal cells (Gameiro et al., 2005), and raised GLP-1 concentrations in turn promote GABA formation by pancreatic $\beta$ cells, with autocrine and paracrine effects, including immunomodulatory actions on infiltrating $\mathrm{T}$ cells to suppress autoimmune damage (Urbain et al., 1990).

Although we have suggested the cytotoxicity observed in our system following RYGB surgery may be a result of putrescine, it may be likely to involve both multiple monoamines such as methylamine, as well as polyamines. Horse serum used in the cell culture medium this study contains high semicarbazide-sensitive amine oxidase (SSAO) activity (Tipnis and He, 1998) which can convert methylamine to formaldehyde, ammonia, and hydrogen peroxide, all of which are cytotoxic (Lyles, 1996; Gubisne-Haberle et al., 2004). SSAO mediated degradation of methylamine has been shown to be cytotoxic to cultured endothelial cells (Yu and Zuo, 1993). Increased tyramine and decreased tyrosine levels were observed in RYGB-operated rats. Tyramine is a monoamine, derived from the microbial enzymatic decarboxylation of tyrosine by various lactic acid bacteria (Komprda et al., 2008) and has also been reported to be produced by Enterobacter spp. strains from food studies on cheese and meat (Marino et al., 2000; Curiel et al., 2011). This is consistent with the marked increase in Enterobacter observed following RYGB surgery. Although tyramine was reported to be mutagenically inactive using the mouse lymphoma assay (McGregor et al., 1988), mutagenesis was only observed after the combined treatment of tyramine and nitrite in vitro (Fujie et al., 1990).

\section{URACIL METABOLISM}

One of the strongest correlates with cytotoxicity following RYGB surgery was fecal uracil levels. Possible rationales for this phenomenon relate to apoptosis and inflammation. There is an increased incidence of apoptosis in inflamed colonic mucosa in cases of inflammatory bowel disease (Afford and Randhawa, 2000) that is associated with impaired mucosal healing (Iwamoto et al., 1996). Uracil has been previously reported to possess anti-apoptotic activity in a human colon epithelial cell line (Evans et al., 2005) and may be produced as a consequence following RYGB surgery in rats to compensate for the ensuing inflammation. An alternative explanation would be modulation of inflammation. Nitric oxide (NO) can be produced from the surrounding tissue and macrophages during inflammatory process, to modulate the extent of inflammation (Nussler and Billiar, 1993) and can react with oxygen to form the nitrosating agent nitrous anhydride which can, in turn, react with nucleophiles, such as amines and thiols (Caulfield et al., 1998). This propensity to react with nucleophiles can lead to nitrosation of primary amine groups in a DNA base leading to direct DNA damage, for example, the deamination of cytosine to uracil (Barnes and Lindahl, 2004). Uracil in genomic DNA can be repaired through excision by Uracil-DNA glycosylase leaving an abasic site creating a substrate for base excision repair (Hagen et al., 2008). It is plausible that uracil may be released during cell lysis caused by the inflammation following RYGB surgery.

\section{PROTECTIVE FUNCTION OF BUTYRATE}

The short chain fatty acid butyrate is produced by bacterial fermentation of dietary fiber and has important physiological roles in maintaining health and integrity of colonic mucosa (Clarke and Mulcahey, 1976). It also regulates colonic epithelial cell proliferation and differentiation. Increased carbohydrate fermentation can divert ammonia, which is toxic to colonic epithelial cells (Lin and Visek, 1991), into de novo bacterial protein synthesis. Butyrate enema treatment has been shown to reduce inflammatory colitis in rats (Butzner et al., 1996). Indeed, the anti-inflammatory role of butyrate through the inhibition of NF- $\kappa$ B activation in cultured human cells from patient biopsies has also been demonstrated (Segain et al., 2000).

\section{CONCLUSION}

The current study has for the first time integrated measures of cytotoxicity with metabolic and microbial phenotypes following bariatric surgery, which may shed some light on the reduced incidence of colonic cancer following weight loss surgery. Various fecal metabolites were found to correlate with cytotoxicity measures. In essence, cytotoxicity was dramatically increased following RYGB in a rat surgical model and this increase was associated with alterations in both the metabolic and the microbial phenotypes with particularly strong correlations between RSG and the Enterobacteriaceae and Pasteurellaceae. The metabolites suggested to be responsible for the cytotoxic effect, based on statistical associations, can be predominantly associated with an inflammatory 
response following surgery, which was persistent over the 8-week study. Although it would have been interesting to follow the cytotoxic profile for a longer period, ethical considerations did not allow this.

In contrast to reports from large-scale human epidemiological cohorts suggesting a reduced cancer risk following bariatric surgery (Ashrafian et al., 2011a), we have demonstrated increased fecal cytotoxicity in this Wistar rat model following RYGB surgery; which can be associated with increased colonic cancer risk (de Kok and van Maanen, 2000). Two possible explanations for the conflicting RYGB effects between humans and rats include: (i) the rat model is not translational to humans with regard to RYGB surgery, or more controversially that the RYGB surgery increases the cytotoxicity of feces, however human colonocytes, are subject to a high degree of oxidative stress and possess enzymes capable of detoxifying $\mathrm{H}_{2} \mathrm{~S}$ and other toxins (Ramasamy et al., 2006), are resistant to this toxicity. The latter explanation however does not clarify

\section{REFERENCES}

Adams, T. D., Gress, R. E., Smith, S. C., Halverson, R. C., Simper, S. C., Rosamond, W. D., Lamonte, M. J., Stroup, A. M., and Hunt, S. C. (2007). Long-term mortality after gastric bypass surgery. N. Engl. J. Med. 357, 753-761.

Afford, S., and Randhawa, S. (2000). Apoptosis. Mol. Pathol. 53, 55-63.

Ashrafian, H., Ahmed, K., Rowland, S. P., Patel, V. M., Gooderham, N. J., Holmes, E., Darzi, A., and Athanasiou, T. (2011a). Metabolic surgery and cancer: Protective effects of bariatric procedures. Cancer 117, 1788-1799.

Ashrafian, H., Athanasiou, T., Li, J. V., Bueter, M., Ahmed, K., Nagpal, K., Holmes, E., Darzi, A., and Bloom, S. R. (2011b). Diabetes resolution and hyperinsulinaemia after metabolic Roux-en-Y gastric bypass. Obes. Rev . 12, e257-272.

Ashrafian, H., Darzi, A., and Athanasiou, T. (2011c). Bariatric surgery: can we afford to do it or deny doing it? Frontline Gastroenterol. 2, 82-89.

Ashrafian, H., Bueter, M., Ahmed, K., Suliman, A., Bloom, S. R., Darzi, A., and Athanasiou, T. (2010). Metabolic surgery: an evolution through bariatric animal models. Obes. Rev. 11, 907-920.

Ashrafian, H., and le Roux, C. W. (2009). Metabolic surgery and gut hormones - a review of bariatric entero-humoral modulation. Physiol. Behav. 97, 620-631.

Barnes, D. E., and Lindahl, T. (2004). Repair and genetic consequences of endogenous DNA base damage in mammalian cells. Annu. Rev. Genet. 38, 445-476.

Beckonert, O., Coen, M., Keun, H. C., Wang, Y., Ebbels, T. M., Holmes,
E., Lindon, J. C., and Nicholson, J. K. (2010). High-resolution magic-angle-spinning NMR spectroscopy for metabolic profiling of intact tissues. Nat. Protoc. 5, 1019-1032.

Bird, J., Mohd-Hidir, S., and Lewis, D. A. (1983). Putrescine - a potent endogenous anti-inflammatory substance in inflammatory exudates. Agents Actions 13, 342-347.

Buckton, G., and Machiste, E. O. (1997). Differences between tension of poly(oxyethylene)-poly (oxypropylene)-poly(oxyethylene) block copolymer surfactants (poloxamers P407, P237, and P338) in aqueous solution. J. Pharm. Sci. 86, 163-166.

Butzner, J. D., Parmar, R., Bell, C. J., and Dalal, V. (1996). Butyrate enema therapy stimulates mucosal repair in experimental colitis in the rat. Gut 38, 568-573.

Casero, R. A. Jr., and Pegg, A. E. (1993). Spermidine/spermine N1acetyltransferase-the turning point in polyamine metabolism. FASEB J. 7, 653-661.

Caulfield, J. L., Wishnok, J. S., and Tannenbaum, S. R. (1998). Nitric oxide-induced deamination of cytosine and guanine in deoxynucleosides and oligonucleotides. J. Biol. Chem. 273, 12689-12695.

Clarke, J. T., and Mulcahey, M. R. (1976). Cytidine-5'-monophospho$\mathrm{N}$-acetylneuraminic acid galactosyl-N-acetylgalactosaminyl(N-acetylneuraminyl)-galactosylglucosylceramide sialyltransferase in the neurohypophysis of the rabbit. Biochim. Biophys. Acta 441, 146-154. dynamic and equilibrium surface

the nature of the decreased cancer risk after bariatric surgery. As these operations are being increasingly performed worldwide within a framework of increased global obesity and metabolic dysfunction (Ashrafian et al., 2011b), an increased understanding of the mechanisms and consequences of bariatric surgery are essential, specifically in terms of cancer risk. The future of this field will require an integrated metabolic, metagenomic, and cytotoxic profiling approach in bariatric patients that have undergone metabolic surgery within robust clinical trials. This can strengthen our understanding of the cancer modifying mechanisms of bariatric surgery to improve the cancer related outcomes associated with metabolic dysfunction and obesity.

\section{ACKNOWLEDGMENTS}

This study was financially supported by the Imperial College London Junior research fellowship to Jia V. Li and from the Wellcome Trust Research Training Fellowship to Hutan Ashrafian.

Clements, J. (2000). The mouse lymphoma assay. Mutat. Res. 455, 97-110.

Cole, J. R., Wang, Q., Cardenas, E., Fish, J., Chai, B., Farris, R. J., KulamSyed-Mohideen, A. S., McGarrell, D. M., Marsh, T., Garrity, G. M., and Tiedje, J. M. (2009). The Ribosomal database project: improved alignments and new tools for rRNA analysis. Nucleic Acids Res. 37, D141-D145.

Curiel, J. A., Ruiz-Capillas, C., de Las Rivas, B., Carrascosa, A. V., Jimenez-Colmenero, F., and Munoz, R. (2011). Production of biogenic amines by lactic acid bacteria and enterobacteria isolated from fresh pork sausages packaged in different atmospheres and kept under refrigeration. Meat Sci. 88, 368-373.

Davis, R. H., Morris, D. R., and Coffino, P. (1992). Sequestered end products and enzyme regulation: the case of ornithine decarboxylase. Microbiol. Rev. 56, 280-290.

de Kok, T. M., and van Maanen, J. M. (2000). Evaluation of fecal mutagenicity and colorectal cancer risk. Mutat. Res. 463, 53-101.

Eckel, R. H., Grundy, S. M., and Zimmet, P. Z. (2005). The metabolic syndrome. Lancet 365, 1415-1428.

Evans, M. E., Jones, D. P., and Ziegler, T. R. (2005). Glutamine inhibits cytokine-induced apoptosis in human colonic epithelial cells via the pyrimidine pathway. Am. J. Physiol. Gastrointest. Liver Physiol. 289, G388-G396.

Evrard, S., Aprahamian, M., Hoeltzel, A., Vasilescu, M., Marescaux, J., and Damge, C. (1993). Trophic and enzymatic adaptation of the intestine to biliopancreatic bypass in the rat. Int
J. Obes. Relat. Metab. Disord. 17, 541-547.

Ferrante, A., Maxwell, G. M., Rencis, V. O., Allison, A. C., and Morgan, D. M. (1986). Inhibition of the respiratory burst of human neutrophils by the polyamine oxidase-polyamine system. Int. J. Immunopharmacol. 8, 411-417.

Fujie, K., Nishi, J., Wada, M., Maeda, S., and Sugiyama, T. (1990). Acute cytogenetic effects of tyramine, MTCAs, $\mathrm{NaCl}$ and soy sauce on rat bone marrow cells in vivo. Mutat. Res. 240, 281-288.

Gameiro, A., Reimann, F., Habib, A. M., O'Malley, D., Williams, L., Simpson, A. K., and Gribble, F. M. (2005). The neurotransmitters glycine and GABA stimulate glucagon-like peptide-1 release from the GLUTag cell line. J. Physiol. (Lond.) 569, 761-772.

Gubisne-Haberle, D., Hill, W. Kazachkov, M., Richardson, J. S., and Yu, P. H. (2004). Protein cross-linkage induced by formaldehyde derived from semicarbazide-sensitive amine oxidase-mediated deamination of methylamine. J. Pharmacol. Exp. Ther. 310, 1125-1132.

Hagen, L., Kavli, B., Sousa, M. M., Torseth, K., Liabakk, N. B., Sundheim, O., Pena-Diaz, J., Otterlei, M., Horning, O., Jensen, O. N., Krokan, H. E., and Slupphaug, G. (2008). Cell cycle-specific UNG2 phosphorylations regulate protein turnover, activity and association with RPA. EMBO J. 27, 51-61.

Iwamoto, M., Koji, T., Makiyama, K., Kobayashi, N., and Nakane, P. K. (1996). Apoptosis of crypt epithelial cells in ulcerative colitis. J. Pathol. $180,152-159$. 
Komprda, T., Burdychova, R., Dohnal, V., Cwikova, O., Sladkova, P., and Dvorackova, H. (2008). Tyramine production in Dutch-type semi-hard cheese from two different producers. Food Microbiol. 25, 219-227.

Kremen, A. J., Linner, J. H., and Nelson, C. H. (1954). An experimental evaluation of the nutritional importance of proximal and distal small intestine. Ann. Surg. 140, 439-448.

Kurihara, S., Kato, K., Asada, K., Kumagai, H., and Suzuki, H. (2010). A putrescine-inducible pathway comprising PuuE-YneI in which gammaaminobutyrate is degraded into succinate in Escherichia coli K-12. J. Bacteriol. 192, 4582-4591.

Laferrere, B., Reilly, D., Arias, S., Swerdlow, N., Gorroochurn, P., Bawa, B., Bose, M., Teixeira, J., Stevens, R. D., Wenner, B. R., Bain, J. R., Muehlbauer, M. J., Haqq, A., Lien, L., Shah, S. H., Svetkey, L. P., and Newgard, C. B. (2011). Differential metabolic impact of gastric bypass surgery versus dietary intervention in obese diabetic subjects despite identical weight loss. Sci. Transl. Med. 3, 80re2.

Lee, Y. K., Hao, W., Ho, P. S., Nordling, M. M., Low, C. S., de Kok, T. M., and Rafter, J. (2005). Human fecal water modifies adhesion of intestinal bacteria to Caco-2 cells. Nutr. Cancer 52, 35-42.

Li, J. V., Ashrafian, H., Bueter, M., Kinross, J., Sands, C., le Roux, C. W., Bloom, S. R., Darzi, A., Athanasiou, T., Marchesi, J. R., Nicholson, J. K., and Holmes, E. (2011). Metabolic surgery profoundly influences gut microbial-host metabolic cross-talk. Gut. 60, 1214-1223.

Lin, H. C., and Visek, W. J. (1991). Colon mucosal cell damage by ammonia in rats. J. Nutr. 121, 887-893.

Lovaas, E., and Carlin, G. (1991). Spermine: an anti-oxidant and antiinflammatory agent. Free Radic. Biol. Med. 11, 455-461.

Lyles, G. A. (1996). Mammalian plasma and tissue-bound semicarbazidesensitive amine oxidases: biochemical, pharmacological and toxicological aspects. Int. J. Biochem. Cell Biol. $28,259-274$.

Mariggio, M. A., Vinella, A., Pasquetto, N., Curci, E., Cassano, A. and Fumarulo, R. (2004). In vitro effects of polyamines on polymorphonuclear cell apoptosis and implications in the pathogenesis of periodontal disease. Immunopharmacol. Immunotoxicol. 26, 93-101.

Marino, M., Maifreni, M., Moret, S., and Rondinini, G. (2000). The capacity of Enterobacteriaceae species to produce biogenic amines in cheese. Lett. Appl. Microbiol. 31, 169-173.

Marton, L. J., Pegg, A. E., and Morris, D. R. (1991). Directions for polyamine research. J. Cell. Biochem. 45, 7-8.

McGregor, D. B., Riach, C. G., Brown, A., Edwards, I., Reynolds, D., West K., and Willington, S. (1988). Reactivity of catecholamines and related substances in the mouse lymphoma L5178Y cell assay for mutagens. Environ. Mol. Mutagen. 11, 523-544.

Mutch, D. M., Fuhrmann, J. C., Rein, D., Wiemer, J. C., Bouillot, J. L., Poitou, C., and Clement, K. (2009). Metabolite profiling identifies candidate markers reflecting the clinical adaptations associated with Rouxen-Y gastric bypass surgery. PLoS ONE 4, e7905. doi: 10.1371/journal.pone. 0007905

Nussler, A. K., and Billiar, T. R. (1993). Inflammation, immunoregulation, and inducible nitric oxide synthase. J. Leukoc. Biol. 54, 171-178.

OECD. (1997). In vitro mammalian cell gene mutation test. OECD Guideline 476

Pegg, A. E. (1988). Polyamine metabolism and its importance in neoplastic growth and a target for chemotherapy. Cancer Res. 48, 759-774.

Quemener, V., Blanchard, Y., Chamaillard, L., Havouis, R., Cipolla, B., and Moulinoux, J. P. (1994). Polyamine deprivation: a new tool in cancer treatment. Anticancer Res. 14, 443-448.

Ramasamy, S., Singh, S., Taniere, P., Langman, M. J., and Eggo, M. C. (2006). Sulfide-detoxifying enzymes in the human colon are decreased in cancer and upregulated in differentiation. Am. J. Physiol. Gastrointest. Liver Physiol. 291, G288-G296.

Schloss, P. D., Westcott, S. L., Ryabin, T., Hall, J. R., Hartmann, M., Hollister, E. B., Lesniewski, R. A., Oakley, B. B., Parks, D. H., Robinson, C. J., Sahl, J. W., Stres, B., Thallinger, G. G., Van Horn, D. J., and Weber, C. F. (2009). Introducing mothur: open-source, platform-independent, communitysupported software for describing and comparing microbial communities. Appl. Environ. Microbiol. 75, 7537-7541.

Segain, J. P., Raingeard de la Bletiere, D., Bourreille, A., Leray, V., Gervois, N., Rosales, C., Ferrier, L., Bonnet, C., Blottiere, H. M., and Galmiche, J. P. (2000). Butyrate inhibits inflammatory responses through NFkappaB inhibition: implications for Crohn's disease. Gut 47, 397-403.

Sjostrom, L., Gummesson, A., Sjostrom, C. D., Narbro, K., Peltonen, M. Wedel, H., Bengtsson, C., Bouchard, C., Carlsson, B., Dahlgren, S., Jacobson, P., Karason, K., Karlsson, J., Larsson, B., Lindroos, A. K., Lonroth, H., Naslund, I., Olbers, T., Stenlof, K., Torgerson, J., and Carlsson, L. M. (2009). Effects of bariatric surgery on cancer incidence in obese patients in Sweden (Swedish Obese Subjects Study): a prospective, controlled intervention trial. Lancet Oncol. 10 653-662.

Tabor, C. W., and Tabor, H. (1984) Polyamines. Annu. Rev. Biochem. 53, 749-790.

Tipnis, U. R., and He, G. Y. (1998) Mechanism of polyamine toxicity in cultured cardiac myocytes. Toxicol. In vitro 12, 233-240.

Tobias, K. E., and Kahana, C. (1995). Exposure to ornithine results in excessive accumulation of putrescine and apoptotic cell death in ornithine decarboxylase overproducing mouse myeloma cells. Cell Growth Differ. 6, 1279-1285.

Tome, M. E., Fiser, S. M., Payne, C. M., and Gerner, E. W. (1997). Excess putrescine accumulation inhibits the formation of modified eukaryotic initiation factor $5 \mathrm{~A}$ (eIF-5A) and induces apoptosis. Biochem. J. 328 , 847-854.

Trygg, J., Holmes, E., and Lundstedt, T. (2007). Chemometrics in metabonomics. J. Proteome Res. 6, 469-479.

Urbain, J. L., Penninckx, F., Siegel, J. A., Vandenborre, P., Van Cutsem, E. Vandenmaegdenbergh, V., and De Roo, M. (1990). Effect of proximal vagotomy and Roux-en-Y diversion on gastric emptying kinetics in asymptomatic patients. Clin. Nucl. Med. 15, 688-691.

Welters, C. F., Dejong, C. H., Deutz, N. E., and Heineman, E. (1999).
Effects of parenteral arginine supplementation on the intestinal adaptive response after massive small bowel resection in the rat. J. Surg. Res. 85, 259-266.

WHO. (2006). Obesity and OverweightFact Sheet No311. Geneva: World Health Organization.

Wing, R. R., and Phelan, S. (2005). Long-term weight loss maintenance. Am. J. Clin. Nutr. 82(1 Suppl.), 222S225S

Yu, P. H., and Zuo, D. M. (1993). Oxidative deamination of methylamine by semicarbazide-sensitive amine oxidase leads to cytotoxic damage in endothelial cells. Possible consequences for diabetes. Diabetes 42, 594-603.

Zhang, H., DiBaise, J. K., Zuccolo, A., Kudrna, D., Braidotti, M., Yu, Y., Parameswaran, P., Crowell, M. D., Wing, R., Rittmann, B. E., and Krajmalnik-Brown, R. (2009). Human gut microbiota in obesity and after gastric bypass. Proc. Natl. Acad. Sci. U.S.A. 106, 2365-2370.

Conflict of Interest Statement: The authors declare that the research was conducted in the absence of any commercial or financial relationships that could be construed as a potential conflict of interest.

Received: 20 May 2011; accepted: 18 August 2011; published online: 13 September 2011

Citation: Li JV, Reshat $R, W u \quad Q$, Ashrafian H, Bueter M, Roux CWl, Darzi A, Athanasiou T, Marchesi JR, Nicholson $J K$, Holmes E and Gooderham NJ (2011) Experimental bariatric surgery in rats generates a cytotoxic chemical environment in the gut contents. Front. Microbio. 2:183. doi: 10.3389/fmicb.2011.00183

This article was submitted to Frontiers in Cellular and Infection Microbiology, a specialty of Frontiers in Microbiology. Copyright (c) 2011 Li, Reshat, Wu, Ashrafian, Bueter, Roux, Darzi, Athanasiou, Marchesi, Nicholson, Holmes and Gooderham. This is an open-access article subject to a non-exclusive license between the authors and Frontiers Media $S A$, which permits use, distribution and reproduction in other forums, provided the original authors and source are credited and other Frontiers conditions are complied with. 